\title{
Noncoal Contractor Mining Facts - 2002
}

The Mine Safety and Health Administration (MSHA) defines an independent contractor as "any person, partnership, corporation, subsidiary of a corporation, firm, association or other organization that contracts to perform services or construction at a mine." Contractors that perform specific types of work are required to report the number of employees who perform work at coal mines and at noncoal mines.

1. In 2002, a total of 4,003 contracting companies reported employment at noncoal mines (metal, nonmetal, sand and gravel, and stone mines) to MSHA.

2. A total of 38,938 noncoal contractor employees, corresponding to 18,533 full-time equivalent (FTE) employees, ${ }^{1}$ were reported to MSHA in 2002. This is a decrease of 21.4\% in FTE noncoal contractor employees from 2001.

- The highest proportion of noncoal contractor employees was found in surface production operations $(68.1 \%){ }^{2}$ followed by processing mills (28.3\%) and underground operations (3.6\%).

3. Six work-related fatalities occurred among noncoal contractor employees in 2002, compared to 10 in 2001.

- In 2002, noncoal contractor employees had a fatality rate of 32.4 per 100,000 FTE employees.

- Three out of the six fatalities occurred in processing mills/preparation plants.

4. There were 318 nonfatal lost-time injuries among noncoal contractor employees, occurring at a rate of 1.7 per 100 FTE employees in 2002. A total of 16,104 days lost from work ${ }^{3}$ resulted from these injuries.

- For noncoal contractor employees, the median number of days lost from work as a result of nonfatal lost-time injuries was 16.0 The median number of days lost from work for noncoal operator employees was 14.0 days.

- The injury rate among noncoal contractor employees in processing mills/preparation plants was 2.2 per 100 FTE employees, compared to 1.8 in underground operations and 1.5 in surface mining operations.

- The most frequently reported types of accidents among noncoal contractor employees were handling material $(n=105 ; 33.0 \%)$ and slips or falls $(n=91 ; 28.6 \%)$.

- Of the most frequently reported injuries (greater than $10 \%$ of total), the most severe injuries (as measured by the median number of days lost from work) were associated with fractures and chips (median = 59 days).

- The back ( $n=45 ; 14.2 \%$ ) was the most frequently reported part of body injured, accounting for 1,511 days lost from work. Injuries to the finger were also frequently reported $(n=44 ; 13.8 \%)$, accounting for 2,169 days lost from work.

- Among noncoal contractor employees, those with the job title of "mechanic/repairman/helper" had the greatest number of nonfatal lost-time injuries $(n=50 ; 15.7 \%)$, followed by those with a job title of "truck driver" ( $n=44 ; 13.8 \%)$.

5. Five cases of occupational illness in noncoal contractor employees were reported to MSHA in $2002{ }^{4}$ There were three cases of heat/sunstroke and one case each of asphyxia and systemic poisoning.

${ }^{1}$ Computed using reported employee hours (2,000 hours = 1 FTE); excludes office employees.

${ }^{2}$ Surface production operations include strip or open pit mines, dredge operations, other surface mining, and independent shops and yards.

${ }^{3}$ Includes actual days away from work and/or days of restricted work activity. For permanently disabling injuries only, statutory days charged by MSHA were used if they exceeded the total lost workdays.

${ }^{4}$ Because of the complexity of attributing disease causation to the workplace, occupational illnesses may be underreported. 


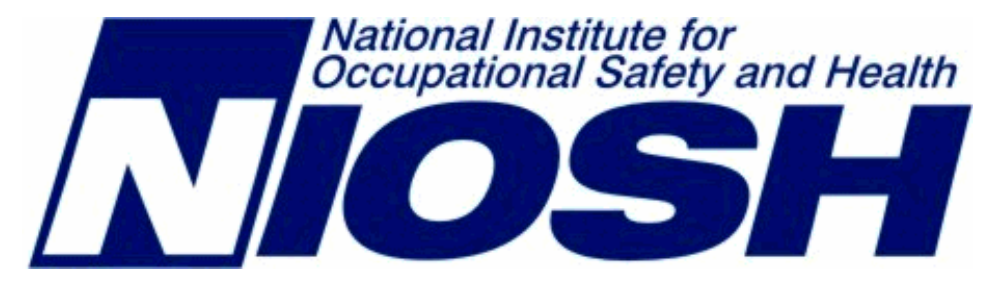

Delivering on the Nation's Promise:

Safety and health at work for all people

Through research and prevention

For information about occupational safety and health topics contact NIOSH at:

1-800-35-NIOSH (1-800-356-4674)

Fax: 513-533-8573

E-mail:pubstaft@cdc.gov

Or visit the NIOSH Mining Web site at www.cdc.gov/niosh/mining

SAFER • HEALTHIER • PEOPLE ${ }^{T M}$

DHHS (NIOSH) Publication No. 2004-129 